\title{
An Overview of Restoration Design and Technical Methods in the Conservation of Architectural Heritage
}

\author{
Qi Kang, Lipeng Zheng \\ State Key Laboratory of Subtropical Building Science, School of Architecture, South China University \\ of Technology, Guangzhou, 510640, China
}

Keywords: Conservation of architectural heritage, Restoration design, Technology

\begin{abstract}
With the rapid development of Chinese cities over the past decade, the architectural heritage representing city development history and cultural heritage is facing the recession even death. For different levels of architectural heritage value and authenticity, we cannot take the traditional fixed standards, and must take the architectural heritage of the culture background into account to take the corresponding protection measures. From the aspects of the structure reinforcement, the appearance of restoration design and preventive protection design, this paper summarizes and analyzes the main points of renovation design and cases to expound the restoration design and technical methods in the conservation of architectural heritage.
\end{abstract}

\section{Introduction}

The chairman of Russian Academy of Conservation Sciences named Prukin pointed out in his article, "twenty-first century protection science should follow the following two principles based repair of scientific theory perfect and systematic, comprehensive and practical repair and restoration of the scientific theory of science and technology integration development. The understanding of protection should be fluid, and should take into account the continuity of life, as well as the past and present needs. It is not only necessary to unify the basic standards, but also need to form a special method for the case.

\section{Strengthening Design of Architecture}

Strengthening of Beam. Beam splitting will have a variety of reasons, some because of the short duration of the use of wood is not dry, the surface and internal shrinkage deformation will be inconsistent, long old cracks; some of it is because the effect of termite infestation, wood from the inside of the hollow, in the long-term pressure bearing structure deformation cracks. For different reasons, different methods should be used to reinforce the structure. In case of harmfulness, need to clean the harmfulness, check the quality of wood can bear the load, according to fill the wood and glue adhesion, such as difficult to continue to use the need to replace the wood, try to choose the same or similar wood processing, according to the admission after replacing the original wood, as shown in Figure 1. In Japan, it creates a way to fit in. When the wood building materials must be replaced, they put the damaged wood removed, and then the wood fasteners tightening method with thousands of years ago to the reconstruction of the ancient buildings. 


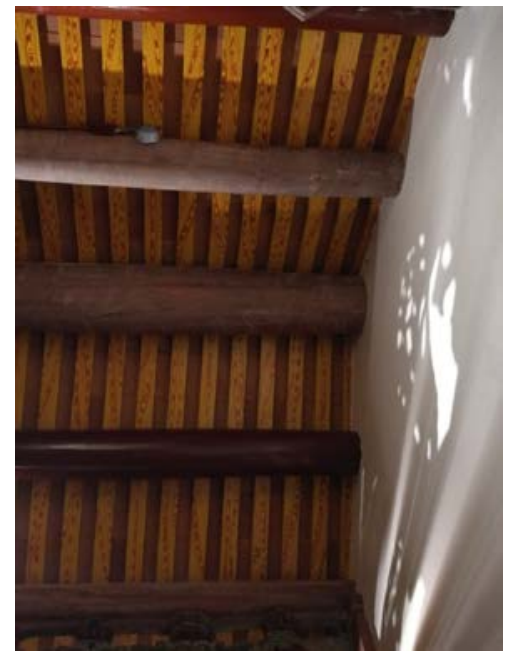

Fig. 1: Purlin used for replacement after restoration of Jiang's family temple

Due to the roof beam member of long-term load weight, generally have a bent phenomenon in different degrees. The Haizhuang temple hall side roof deformation bend down, if not bent without reinforcement. However, if the general pine beam, if the ratio of the vertical and span of the beam is greater than $1 / 120$, we should take measures to strengthen the beam at the bottom of the bending part of the top pillar to reinforce. When the components of tilt beam system, load dispersion release member bear, members will tilt, dislocation, rolling back, in order to prevent the future may continue to appear inclined, generally again fixed connection structure. If because of large wooden architecture in inclined tenon bit, short column is fixed after the structure distortion, the component can be re homing.

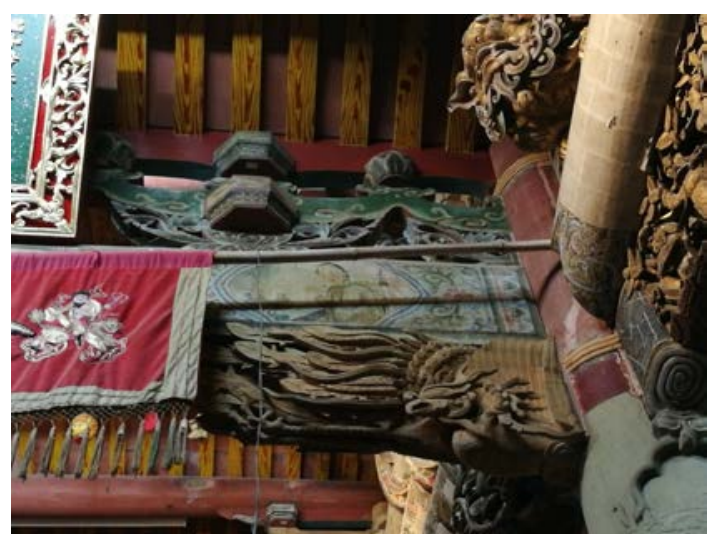

Fig. 2: Interior scenes of Jiang's family temple

Strengthening of Column. Chinese ancient pillars are round, square or octagonal cross section, columns belong to the vertical force component, mainly used to erect bearing beam. The roof beam, the weight of scattered to all landing on the pillars by the column to column bases, finally transferred to the foundation. Some of the columns that are placed between the beam and the beam are not only used as members of the force transfer. Pillars of the material can be divided into two kinds of wood and stone. Generally, the problem of the structure of the stone column is not large, only considering the influence of weathering. The influence of wood was susceptible to infestation, humidity change, structure deformation leads to the decrease of bearing capacity. The tenon and mortise structure used in the wooden structure of ancient buildings is similar to a semi steel connection. The column uses tenon and mortise to fix its position, but when the horizontal and vertical load is too large, the column tenon and mortise structure is destroyed, and the bearing capacity of the column is reduced. The right column Jiang's family temple pink tangent is to remove termites and fill the wood after the traces left behind. After the carbon fiber coated wooden compressive strength parallel to grain and the ultimate compressive bearing capacity has been significantly improved, and the reinforcement in a different way as the increase rate ranges from $18 \%$ to $33 \%$.

Earthquake Resistant Design. The protection of the cultural relics building has always been to follow the "not changing the original" principle, but also has the following principles for maintenance 
and reinforcement: only for the original structure of raw materials for repairing and reinforcing, not to replace the raw materials with modern materials. This principle mainly takes into account the ancient architecture of the wooden structure is different from the modern architectural theory, which has its own unique system, and therefore cannot blindly apply the modern theory of structural safety assessment. However, in the actual restoration project in the ancient building has natural and man-made destruction of the destruction of a variety of possibilities. According to the ancient wooden structure, for the construction of hierarchical inspection and replacement to have offset structure of the recovery, repair the damage to the replacement of small components, while retaining the original structure under the condition of raw materials should be allowed to choose a new wood similar performance change. For the serious settlement of the foundation and other serious hidden danger to be corrected as soon as possible.

\section{Restoration Design of Architectural Appearance}

Doors and Windows. The repairmen of the doors and windows needs based on respect for historical status, on the basis of the restoration for windows and doors remaining, it should keep its window style, check the damaged wood, tenon and its reinforcement; unable to continue to use, should be in accordance with the original style and size have been deleted again; for the window sash. Around the same time, we should refer to the same type of window style to recover the missing windows.

Roofing. After years, the building roof baptism are prone to damage, collapse and leakage problems. The damaged roofing tile roof waterproof function is greatly reduced, the rain infiltration on the wood roof will destroy the original painted patterns, its structure is also prone to rot, causing splitting and breaking, the use of building safety hazards. Level of protection for different roof surface damage and architectural heritage, choose the suitable method for repairing pavement renovation. Maximum preservation of cultural relics of the original part of the building, as far as possible to avoid adding and removing. In the ancient architecture of the remaining components can be used to repair the repair back. Paving the way should be laid in accordance with the original, and the number of original corrugated tiles and even paved traces consistent. The roof should be kept for the original fold, according to historical data on the cornice laying tile and water recovery.

Exterior Walls. As one of the main components of the building load, the wall provides the waterproof, windproof, thermal insulation and thermal insulation performance. We take the Cheng'ai Book Store in Jiaocunshi street of Guangzhou city, the facade of the craft rubbed brickwork wall with high grade specifications with the mill to grind brick masonry, the glutinous rice as adhesive, dry swing grouting between the bricks, wall hanging ash no, the whole wall painted red, smooth, seamless. On the wall brush, a few times light coal water and light coal water after dry, but also with cotton dipped wax rubbing repeatedly until the wall. This kind of process is complicated, and the time is longer, so the cost is higher. In view of this kind of special construction technique, we should try our best to restore the original shape and style in the repair process.

Sculpture. The construction of the sculpture according to the different materials can be divided into brick, cement and wood carving. In the repair process for the original sculpture to retain as much as possible to retain, for missing, stolen or damaged severely carved components to find the historical basis, please craftsmen in accordance with historical evidence to restore the traditional method. Taking Taiwan County of Hsinchu North Street on the south side of the Pu Jiang's temple as an example, the building of Taiwan as the monuments in the repair at the beginning of the ontology building severely damaged. Design unit as a historical evidence to hire skilled craftsmen to restore the original sculpture, are in accordance with the historical data as far as possible to restore. Jiang's family temple there is a part of the sculpture is the people re painted, covering its original features, in order to reproduce the history, design units use a variety of cleaning solvents tested in the repair process, determine the use of cleaning agent can reduce the damage and restore the original appearance of the original painting. 


\section{Preventive Protection Design}

For the restoration of historic buildings, the need to consider the risk of damage to the building itself, so the design should try to improve the preventive protection facilities, to prevent to protect buildings in unexpected incidents, reduce losses. For the construction of the site, need to take into account the harm caused by groundwater level terrain, avoid the water level, leading to the construction of basic structure damp, in the actual construction should not only reduce or discharge of groundwater, groundwater has established the detection pool or other equipment, to prevent water level due to rainfall increased, as shown in Figure 3. In order to detect the underground water level, the water reservation was protected before Jiang's temple. From the perspective of prevention, the lightning protection facilities reducing building lightning probability.

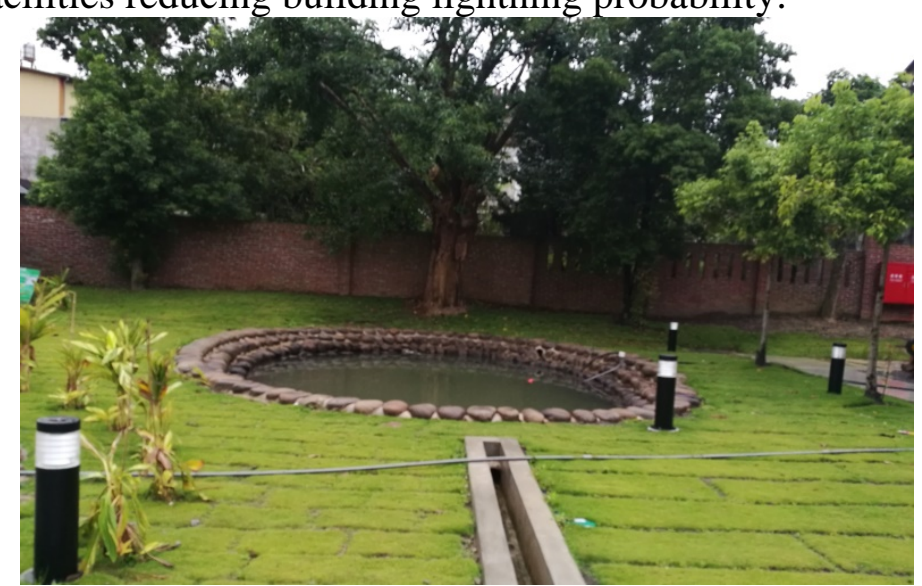

Fig. 3: Pool before the Jiang's family temple

\section{Conclusion}

Architectural heritage is an important achievement of the materialization of human civilization, and it is an important achievement in the history of human civilization. In the recent ten years, the protection of historical buildings in our country is increasingly mature, and the awareness and ability of protection has been improved. Design and construction personnel should learn more and more about the traditional repairing technology and modern new technology, the use of flexible architectural heritage renovation practice, many consider the actual construction work before, during and after the period, combined with the design, construction, repair and evaluation system, and promote the building repair work orderly and clearly. We should better protect the architectural heritage to reproduce the old style in the modern society.

\section{References}

[1] Ma Jianxun, Hu Ping, Jiang Xiangmin, Hu Ming, Experimental Research on Axial Compressive Behaviors for Timber Column Strengthened with CFRP [J]. Industrial Construction, 2005, 35(8): 40-44+55.

[2] Chen Wei, He Huan, Hu Bin, Renovation Design of Shimazhen Original Church in Dazu County, Chongqing [J]. Journal of Human Settlements in West China, 2012(6): 43-48.

[3] Zheng Shiling, Architectural Heritage Conservation in Shanghai and Its Reflection [J]. Heritage Architecture, 2016(1): 10-23.

[4] Cai Qing, Yao Tang, Feature Maintenance and Style Restoration of Landscape Heritages [J]. Journal of Landscape Research, 2009, 1(7):35-39. 